Article

\title{
Phytochemical Analysis, Antioxidant and Antimicrobial Activities of Helichrysum arenarium (L.) Moench. and Antennaria dioica (L.) Gaertn. Flowers
}

\author{
Mihai Babotă ${ }^{1}$, Andrei Mocan ${ }^{1}$, Laurian Vlase ${ }^{2, *(1)}$, Ovidiu Crișan ${ }^{3, *}$, Irina Ielciu ${ }^{1}$, \\ Ana-Maria Gheldiu ${ }^{2}$, Dan Cristian Vodnar ${ }^{4}$, Gianina Crișan ${ }^{1,+}$ and Ramona Păltinean ${ }^{1,+}$ \\ 1 Department of Pharmaceutical Botany, “Iuliu Hațieganu” University of Medicine and Pharmacy, \\ 400337 Cluj-Napoca, Romania; babotamihai95@gmail.com (M.B.); mocan.andrei@umfcluj.ro (A.M.); \\ irina.ielciu@umfcluj.ro (I.I.); gcrisan@umfcluj.ro (G.C.); rpaltinean@umfcluj.ro (R.P.) \\ 2 Department of Pharmaceutical Technology and Biopharmaceutics, "Iuliu Hațieganu" University of \\ Medicine and Pharmacy, 400010 Cluj-Napoca, Romania; gheldiu.ana@umfcluj.ro \\ 3 Department of Organic Chemistry, “Iuliu Hațieganu” University of Medicine and Pharmacy, \\ 400010 Cluj-Napoca, Romania \\ 4 Department of Food Science, University of Agricultural Sciences and Veterinary Medicine, \\ 400372 Cluj-Napoca, Romania; dan.vodnar@usamvcluj.ro \\ * Correspondence: laurian.vlase@umfcluj.ro (L.V.); ocrisan@umfcluj.ro (O.C.); Tel.: +40-264-595770 (L.V.); \\ +40-264-593767 (O.C.) \\ + These authors contributed equally to this work.
}

Received: 11 December 2017; Accepted: 17 January 2018; Published: 13 February 2018

\begin{abstract}
Antennaria dioica (L.) Gaertn. and Helichrysum arenarium (L.) Moench. are two species of the Asteraceae family, known in Romanian traditional medicine for their diuretic, choleretic, and anti-inflammatory properties. The aim of the present study was to evaluate the phenolic and sterolic composition of flowers from the two species and to assess their antioxidant, antibacterial and antifungal properties. LC-MS analyses were performed on methanolic, ethanolic and $70 \% v / v$ ethanolic extracts, before and after acid hydrolysis, and revealed high amounts of polyphenols. Chlorogenic acid was found as the main compound for the flowers of A. dioica (502.70 \pm $25.11 \mathrm{mg} / 100 \mathrm{~g}$ d.w.), while quercitrin was dominant in H. arenarium $(424.28 \pm 21.21 \mathrm{mg} / 100 \mathrm{~g}$ d.w.) in $70 \% v / v$ ethanolic extracts before hydrolysis. Antioxidant capacity assays showed an important antioxidant potential, which can be correlated with the determined polyphenolic compounds, showing the $70 \% v / v$ ethanolic extracts of the two species as being the most effective antioxidant samples for the DPPH assay. Antibacterial and antifungal assays confirm a modest biological potential for the same extract of both species. Results obtained in the present study bring important data and offer scientific evidence on the chemical composition and on the biological activities of the flowers belonging to the two species.
\end{abstract}

Keywords: H. arenarium; A. dioica; polyphenolic profile; LC-MS; antibacterial activity; antifungal activity; antioxidant capacity

\section{Introduction}

The Asteraceae family, which comprises more than 1600 genera, with over 23,000 species, widespread in different types of climates and regions all over the world, is the largest family of flowering plants $[1,2]$. The diversity and heterogeneity of this family justifies the great importance of its individual members, which are known and used from ancient times, not only as food sources or as spices, but also for medicinal purposes [3,4]. Several classes of compounds from Asteraceae species were studied and tested for different bio-activities and were reported as having medicinal potential [3-5]. 
Among these compounds, a special attention has been given to polyphenols, and especially to flavonoids, which provide for these species important uses in the pharmaceutical, cosmetics and food industry, that are due to their important medicinal properties as the antioxidant, anti-inflammatory, antifungal or antibacterial ones [4]. In this context and taking into consideration the fact that in the last decades these compounds have shown a significant importance in the field of medicinal compounds, the Asteraceae species should be reconsidered as possible sources of flavonoids and polyphenols, generally.

Antennaria dioica (L.) Gaertn. and Helichrysum arenarium (L.) Moench. (Figure 1) are two species belonging to the same tribe (Gnaphalieae) [6,7] of the Asteraceae family [8,9]. These species are widespread across the European continent, especially in Central and Eastern countries and are known in traditional medicine for their use in the treatment of different pathologies. The connection between these species relies on several common morphological characters and it is confirmed by phylogenetic studies [10,11], which certify their common taxonomic classification. The folk medicine of different countries cites common uses for herbal preparations obtained from the flowers of these species, exploited for their diuretic [12,13], choleretic and anti-inflammatory properties [13-15]. Romanian sources mention both under the same phytonyme, describing their use for the treatment of jaundice [16]. Few scientific evidence exists up to date in order to support these data and a more detailed study of the two species becomes therefore important.

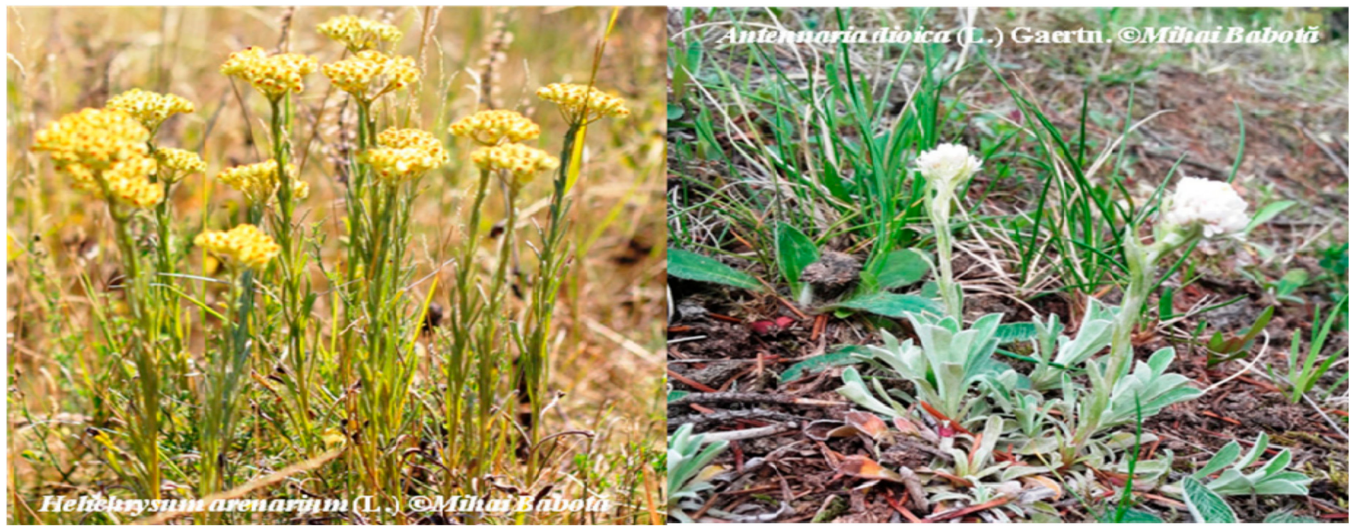

Figure 1. Helichrysum arenarium (L.) and Antennaria dioica (L.) Gaertn.

A. dioica is a perennial herb, commonly found in dry grasslands and sandy or stony places from Eurasian areas, where it is traditionally used to treat biliary and respiratory ailments [13,15], and also for its astringent and hemostatic properties $[13,17]$. To date, few scientific data were reported regarding the chemical composition of this species. Merili et al. [15] studied the extracts obtained from the flowers of $A$. dioica and isolated ursolic acid, chlorogenic acid, apigenin-7-O-glucoside and luteolin-7-O-glucoside. To the best of our knowledge, this is the only existing scientific study that describes the flavonoid composition of this species, and it does not establish a connection between the potential bioactivities of the species and the isolated compounds.

Helichrysum species were known from ancient times due to a large distribution and diversity and are cited as being a potent remedy for various pathologies $[12,14,18]$. Among the species of this genus, a special importance was given to $H$. arenarium, which is the most popular species, having monographs in different pharmacopoeias, such as the Russian Pharmacopoeia [14]. Several studies aimed to investigate the phytochemical profile of H. arenarium and to evaluate its potential bio-activities [16-20]. Major constituents of the extracts obtained from the flowers of H. arenarium are polyphenols, especially flavonoids [19-23], usually found as glycosides. The connection between the phenolic content of this species and its antioxidant, anti-inflammatory and antimicrobial activities was studied by different authors [19-21]. Other studies focused on the investigation of the volatile compounds. In this regard, Rančić et al. [24] showed that the essential oil from H. arenarium flowers has an important antimicrobial 
potential. All existing data remain nevertheless scarce and do not establish a clear chemical composition of the flowers and their connection with the cited biological activities.

Both species are used for different purposes in Romanian traditional medicine, but, despite this fact, few scientific data about the chemical composition and biological activities of A. dioica and $H$. arenarium collected from the Romanian spontaneous flora were reported so far. Grădinaru et al. investigated the phenolic content and antibacterial activity of a methanolic extract obtained from the inflorescences of Helichrysum arenarium (L.) Moench subsp. arenarium against lower respiratory tract pathogens, being the only existing scientific study about a Romanian Helichrysum sample [22]. Nonetheless, no scientific data with regard to Romanian A. dioica exist to date.

Within this frame, the present study aimed to investigate the phenolic, flavonoidic and sterolic composition of A. dioica (L.) Gaertn. and H. arenarium (L.) Moench. collected from the Romanian spontaneous flora and to assess their antioxidant and antimicrobial properties. Thus, the present study represents a starting point for a most detailed study of the two species, demonstrating their important potential as sources of bioactive compounds.

\section{Results and Discussion}

\subsection{HPLC-MS Analysis of Polyphenolic Compounds}

Qualitative and quantitative evaluation of phenolic compounds in the composition of the methanolic $(\mathrm{MeOH})$, ethanolic $(\mathrm{EtOH})$ and $70 \%(v / v)$ ethanolic $(\mathrm{EtOH} 70 \%)$ extracts obtained from the flowers of $A$. dioica and $H$. arenarium was achieved using an HPLC-MS method. The method was previously applied for the phytochemical analysis of different plant samples and provided good results $[25,26]$. Each sample was analyzed before and after acid hydrolysis in order to obtain more accurate data on the composition in flavonoid glycosides and their aglycones [26].

Among the 19 phenolic compounds used as standards, 9 compounds could be detected and quantified in hydrolyzed samples and 7 in non-hydrolyzed ones (Tables 1 and 2). The external standard method was used for quantification, and results were expressed as mg compound/100 g dry weight (d.w.) herbal material.

Before hydrolysis, the sample that proved to contain the largest number of polyphenolic compounds was the $70 \%(v / v)$ ethanolic extract of the flowers of $H$. arenarium. In this sample, chlorogenic acid $(340.95 \pm 17.04 / 100 \mathrm{~g}$ d.w. $)$ and quercitrin $(424.28 \pm 21.21 \mathrm{mg} / 100 \mathrm{~g}$ d.w. $)$ were found in the highest amounts. High amounts of quercitrin were also found in the methanolic (438.33 \pm $21.91 \mathrm{mg} / 100 \mathrm{~g} \mathrm{d.w})$ and ethanolic $(409.09 \pm 20.45 \mathrm{mg} / 100 \mathrm{~g} \mathrm{d.w}$.) extracts of this species.

Similar results were obtained for the non-hydrolyzed extracts of $A$. dioica. Before hydrolysis, the most abundant compounds were chlorogenic acid (502.70 $\pm 25.11 \mathrm{mg} / 100 \mathrm{~g}$ d.w.) for the $70 \%(v / v)$ ethanolic extract, while for the methanolic and ethanolic extracts quercitrin was determined in the highest amount (methanolic extract: $444.48 \pm 22.22 \mathrm{mg} / 100 \mathrm{~g}$ d.w., ethanolic extract: $147.64 \pm$ $7.38 \mathrm{mg} / 100 \mathrm{~g}$ d.w.). Chlorogenic acid was also found in a significant amount in the methanolic extract (434.18 $\pm 21.70 \mathrm{mg} / 100 \mathrm{~g}$ d.w.).

After the acid hydrolysis, the presence of quercetol was determined in all samples, the $70 \%(v / v)$ ethanolic extract of $H$. arenarium containing the highest amount of this compound (26.16 \pm $1.30 \mathrm{mg} / 100 \mathrm{~g}$ d.w.). A possible explanation of this fact is correlated with the decreasing amounts of isoquercitrin and quercitrin which partially hydrolyse into quercetol.

Our results indicate that major phenolic compounds of $H$. arenarium extracts are flavonoids (i.e., quercitrin, isoquercitrin). Other studies concerning the polyphenolic profile of this species were performed by Albayrak et al. [21] and Grinev et al. [23]. Their results show important amounts of phenolic compounds that are proved to be the main compounds in the extracts of this species (e.g., chlorogenic acid, quercetol, apigenin). Furthermore, using an HPLC-DAD-ESI-MS method, Grădinaru et al. [22] identified apigenin, kaempferol, chlorogenic acid, and caffeic acid in the composition of a methanolic extract obtained from $H$. arenarium ssp. arenarium flowers. The assays 
performed by the present study confirm the results obtained by these authors. However, this study brings novelty and originality, being the first report about the composition in phenolic compounds, such as $p$-coumaric acid, isoquercitrin, quercitrin and luteolin in the flowers of the Romanian H. arenarium.

Table 1. The phenolic compounds identified in the flowers of $H$. arenarium and A. dioica extracts before acid hydrolysis (mg/100 g d.w.).

\begin{tabular}{|c|c|c|c|c|c|c|}
\hline \multirow{2}{*}{$\begin{array}{l}\text { Phenolic } \\
\text { Compound }\end{array}$} & \multicolumn{3}{|c|}{ H. arenarium (L.) Moench. } & \multicolumn{3}{|c|}{ A. dioica (L.) Gaertn. } \\
\hline & $\mathrm{MeOH}$ & EtOH & EtOH 70\% & $\mathrm{MeOH}$ & EtOH & EtOH $70 \%$ \\
\hline Chlorogenic acid & $177.70 \pm 8.88$ & $111.58 \pm 5.57$ & $340.95 \pm 17.04$ & $434.18 \pm 21.70$ & $84.59 \pm 4.22$ & $502.70 \pm 25.11$ \\
\hline Isoquercitrin & $70.18 \pm 3.50$ & $57.45 \pm 2.87$ & $85.55 \pm 4.27$ & NF & NF & NF \\
\hline Quercitrin & $438.33 \pm 21.91$ & $409.09 \pm 20.45$ & $424.28 \pm 21.21$ & $444.48 \pm 22.22$ & $147.64 \pm 7.38$ & $240.41 \pm 12.02$ \\
\hline Luteolin & $9.34 \pm 0.46$ & $8.66 \pm 0.43$ & $9.98 \pm 0.49$ & NF & NF & NF \\
\hline
\end{tabular}

Note: Values represent the mean $\pm \mathrm{SD}$ (standard deviation); $\mathrm{NF}=$ not found, below the limit of quantification.

Table 2. The phenolic compounds identified in the flowers of $H$. arenarium and A. dioica extracts after acid hydrolysis (mg/100 g d.w.).

\begin{tabular}{|c|c|c|c|c|c|c|}
\hline \multirow{2}{*}{$\begin{array}{l}\text { Phenolic } \\
\text { Compound }\end{array}$} & \multicolumn{3}{|c|}{ H. arenarium (L.) Moench. } & \multicolumn{3}{|c|}{ A. dioica (L.) Gaertn. } \\
\hline & $\mathrm{MeOH}$ & EtOH & EtOH 70\% & $\mathrm{MeOH}$ & EtOH & EtOH 70\% \\
\hline Chlorogenic acid & $73.63 \pm 3.68$ & $64.07 \pm 3.20$ & $224.39 \pm 11.21$ & $38.43 \pm 1.92$ & $27.97 \pm 1.39$ & $246.55 \pm 12.32$ \\
\hline$p$-Coumaric acid & $2.65 \pm 0.13$ & $2.16 \pm 0.10$ & $4.40 \pm 0.22$ & $3.17 \pm 0.15$ & $2.41 \pm 0.12$ & $13.13 \pm 0.65$ \\
\hline Ferulic acid & NF & $\mathrm{NF}$ & $4.08 \pm 0.20$ & NF & NF & NF \\
\hline Isoquercitrin & NF & NF & $13.89 \pm 0.69$ & NF & NF & NF \\
\hline Quercitrin & $7.25 \pm 0.36$ & $9.19 \pm 0.45$ & $15.85 \pm 0.79$ & $63.04 \pm 3.15$ & $69.38 \pm 3.46$ & $89.65 \pm 4.48$ \\
\hline Quercetol & $23.31 \pm 1.16$ & $20.68 \pm 1.03$ & $26.16 \pm 1.30$ & $12.17 \pm 0.60$ & $9.34 \pm 0.46$ & $19.66 \pm 0.98$ \\
\hline Luteolin & $5.76 \pm 0.28$ & $7.19 \pm 0.35$ & $9.09 \pm 0.45$ & $128.15 \pm 6.40$ & $104.70 \pm 5.23$ & $183.52 \pm 9.17$ \\
\hline Kaempferol & $181.23 \pm 9.06$ & $175.63 \pm 8.78$ & $179.28 \pm 8.96$ & $1.95 \pm 0.09$ & $0.85 \pm 0.04$ & $1.89 \pm 0.09$ \\
\hline Apigenin & $69.79 \pm 3.48$ & $61.87 \pm 3.09$ & $59.07 \pm 2.95$ & $20.79 \pm 1.03$ & $16.71 \pm 0.83$ & $24.31 \pm 1.21$ \\
\hline
\end{tabular}

Note: Values represent the mean $\pm \mathrm{SD}$ (standard deviation); $\mathrm{NF}=$ not found, below the limit of quantification.

Regarding the phenolic profile of $A$ dioica, our results correlate with the previous report of Merili et al. [15], which described the presence of chlorogenic acid, luteolin and apigenin, while providing, at the same time, new data on the presence of kaempferol (in the largest amount in the methanolic extract: $45.67 \pm 2.28 \mathrm{mg} / 100 \mathrm{~g} \mathrm{d.w}$.) and quercitrin (in the largest amount in the methanolic extract: $444.48 \pm 22.22 \mathrm{mg} / 100 \mathrm{~g} \mathrm{~d} . \mathrm{w}$.) in the non-hydrolyzed samples. Luteolin could be identified only in hydrolyzed samples, being found in the highest amount in the 70\% ethanolic extract (183.52 $\pm 9.17 \mathrm{mg} / 100 \mathrm{~g}$ d.w.), together with $p$-coumaric acid (13.13 $\pm 0.65 \mathrm{mg} / 100 \mathrm{~g}$ d.w.), quercetol (19.66 $\pm 0.98 \mathrm{mg} / 100 \mathrm{~g}$ d.w.) and quercitrin (89.65 $\pm 4.48 \mathrm{mg} / 100 \mathrm{~g}$ d.w.).

\subsection{HPLC-MS Analysis of Methoxylated Flavones}

Among the tested methoxylated flavones, only hispidulin could be determined. Amounts that have been quantified do not exceed $1 \mathrm{mg} / 100 \mathrm{~g} \mathrm{~d} . \mathrm{w}$. The sample that proved to contain the highest amount of hispidulin was the methanolic extract of $H$. arenarium $(0.70 \pm 0.03 \mathrm{mg} / 100 \mathrm{~g} \mathrm{~d} . w$.). Generally, this species proved to contain the largest amounts of hispidulin, while the amounts that are found in A. dioica are much lower (Table 3). This is the first report that assesses the amounts of methoxylated flavones among the components of the two species. 
Table 3. The methoxylated flavones identified in the flowers of $H$. arenarium and A. dioica extract (mg/100 g d.w.).

\begin{tabular}{ccccccc}
\hline \multirow{2}{*}{ Methoxylated Flavone } & \multicolumn{3}{c}{ Helichrysum arenarium } & \multicolumn{3}{c}{ Antennaria dioica } \\
\cline { 2 - 7 } & $\mathbf{M e O H}$ & EtOH & EtOH 70\% & MeOH & EtOH & EtOH 70\% \\
\hline Hispidulin & $0.70 \pm 0.03$ & $0.68 \pm 0.03$ & $0.68 \pm 0.01$ & $0.29 \pm 0.01$ & $0.22 \pm 0.01$ & $0.33 \pm 0.01$ \\
\hline
\end{tabular}

\subsection{HPLC-MS Analysis of Phytosterols}

Five phytosterols were analyzed by an HPLC-MS method in the composition of the flowers belonging to the two species. Among these compounds, the highest amounts were found for $\beta$-sitosterol. Methanolic extracts of the flowers proved to be the richest samples in this compound: $37.04 \pm 1.85 \mathrm{mg} / 100 \mathrm{~g}$ d.w. for H. arenarium, and $63.77 \pm 3.18 \mathrm{mg} / 100 \mathrm{~g}$ d.w. for A. dioica. Lower amounts were found for stigmasterol and campesterol (Table 4).

Table 4. The sterolic compounds identified in the flowers of $H$. arenarium and A. dioica extracts (mg/100 g d.w.).

\begin{tabular}{ccccccc}
\hline \multirow{2}{*}{$\begin{array}{c}\text { Sterolic } \\
\text { Compound }\end{array}$} & \multicolumn{3}{c}{ Helichrysum arenarium } & \multicolumn{3}{c}{ Antennaria dioica } \\
\cline { 2 - 7 } & $\mathbf{M e O H}$ & EtOH & EtOH 70\% & MeOH & EtOH & EtOH 70\% \\
\hline Campesterol & $1.04 \pm 0.05$ & $0.82 \pm 0.04$ & $0.80 \pm 0.03$ & $1.36 \pm 0.06$ & $0.95 \pm 0.04$ & $1.50 \pm 0.07$ \\
Stigmasterol & $6.17 \pm 0.30$ & $4.37 \pm 0.21$ & $5.40 \pm 0.21$ & $4.72 \pm 0.23$ & $2.90 \pm 0.14$ & $4.79 \pm 0.23$ \\
$\beta$-Sitosterol & $37.04 \pm 1.85$ & $26.21 \pm 1.31$ & $26.21 \pm 1.04$ & $63.77 \pm 3.18$ & $45.92 \pm 2.29$ & $67.58 \pm 3.37$ \\
\hline
\end{tabular}

Note: Values represent the mean \pm SD (standard deviation).

\subsection{Antioxidant Activity Assays}

\subsubsection{Trolox Equivalents Antioxidant Capacity (TEAC) Assay}

The TEAC assay is based on electron transfer reactions to evaluate radical scavenging activity of various compounds or complex samples. The antioxidant activity against the stable synthetic ABTS radical cation of the different $H$. arenarium and A. dioica extracts is summarized in Table 5. Some differences have been found in the antioxidant activities of the samples. The highest antioxidant activity was found for the $70 \%(v / v)$ ethanolic extract of the flowers belonging to both species $(5.71 \mathrm{TE} / \mathrm{mL}$ and $5.82 \mathrm{TE} / \mathrm{mL}$ extract, for $A$. dioica and $H$. arenarium, respectively) and the lowest in the absolute ethanol-mediated extraction samples $(2.65 \mathrm{TE} / \mathrm{mL}$ and $3.71 \mathrm{TE} / \mathrm{mL})$. Previous data concerning the antioxidant activity of $H$. arenarium were obtained by Kiselova et al. [27] using the TEAC assay on Bulgarian $H$. arenarium. These authors indicated that aqueous extract of the investigated species possess a value of $1.50 \pm 0.06 \mathrm{mM}$ TE. Nevertheless, it is not possible to compare the present results with those from the literature, because of the different ways of expression, and/or the different preparation method/type of sample.

Table 5. Antioxidant capacity parameters obtained using several methods for studied samples.

\begin{tabular}{cccc}
\hline \multicolumn{2}{c}{ Samples } & TEAC $(\mathbf{m g}$ TE/mL) & DPPH (mg TE/mL) \\
\hline \multirow{4}{*}{ A. dioica } & MeOH & $3.89 \pm 0.01$ & $13.44 \pm 1.65$ \\
& EtOH & $2.65 \pm 0.01$ & $5.89 \pm 1.23$ \\
& EtOH 70\% & $5.71 \pm 0.01$ & $15.21 \pm 1.97$ \\
\hline \multirow{3}{*}{ H. arenarium } & MeOH & $4.04 \pm 0.01$ & $4.91 \pm 1.90$ \\
& EtOH & $3.71 \pm 0.01$ & $7.21 \pm 2.81$ \\
& EtOH 70\% & $5.82 \pm 0.02$ & $17.88 \pm 7.20$ \\
\hline
\end{tabular}

Note: Values represent the mean $\pm \mathrm{SD}$ (standard deviation). 


\subsubsection{DPPH Assay}

DPPH is a stable free stable radical and its absorbance maximum occurs at $517 \mathrm{~nm}$. The higher the rate of DPPH consumption is, the more powerful the antioxidant potential. The results obtained from the DPPH assay were presented as Trolox equivalents (Table 5). The values obtained for A. dioica are in accordance with the values obtained from TEAC assay. The $70 \%(v / v)$ ethanolic extract possessed the highest value $(15.21 \mathrm{mg} \mathrm{TE} / \mathrm{mL})$, whereas the absolute ethanolic extract showed a value of $5.89 \mathrm{mg} \mathrm{TE} / \mathrm{mL}$. There are few available data regarding the antioxidant capacity of Antennaria species. In this case, a comparison with the results of other researchers is not possible. In contrast to this, there are various studies regarding the antioxidant proprieties of $H$. arenarium. Albayrak et al. [28] indicated that the extract of the investigated species possessed an $\mathrm{IC}_{50}$ value of $37.52 \mu \mathrm{g} / \mathrm{mL}$. Moreover, different subspecies of $H$. arenarium were investigated for their antioxidant proprierties by Albayrak et al. [21] and the results, expressed as $\mathrm{IC}_{50}$, were: $23.03 \mu \mathrm{g} / \mathrm{mL}$ for subsp. erzincanicum, $47.64 \mu \mathrm{g} / \mathrm{mL}$ for subsp. rubicundum, $27.32 \mu \mathrm{g} / \mathrm{mL}$ for subsp. araxinum and $38.82 \mu \mathrm{g} / \mathrm{mL}$ for subsp. pseudoplicatum. Due to different ways of expression, these results are not comparable, and, therefore, further studies are necessary for the evaluation of antioxidant capacity, in correlation with other species/subspecies. Nonetheless, the maximum antioxidant capacity is expressed in all cases in the $\mathrm{EtOH} 70 \%(v / v)$ extract, which is correlated to the data obtained for phenolic composition of the extracts.

\subsection{Determination of Total Phenolic Content (TPC) and Total Flavonoid Content (TFC)}

Besides the identified compounds, many other phenolic compounds are found in the flowers of $H$. arenarium and A. dioica and contribute to their antioxidant activity. A comparative overview of the total phenolic and flavonoid contents of the different extracts of the flowers of $H$. arenarium and A. dioica species was performed. The total phenolic content (TPC) ranged from $13.74 \mathrm{mg}$ GAE/g d.w. ethanolic extracts of H. arenarium to $36.27 \mathrm{mg} \mathrm{GAE} / \mathrm{g}$ d.w. for $70 \%(v / v)$ ethanolic extract of $A$. dioica extract (Figure 2).

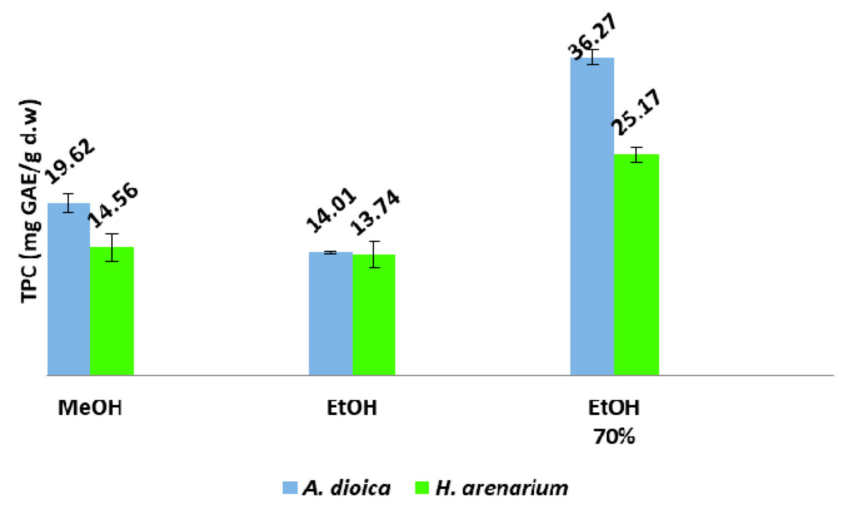

Figure 2. Total phenolic content (TPC) of H. arenarium and A. dioica flowers.

In both cases, the highest values in terms of total phenolic content were obtained by using $70 \%(v / v)$ ethanol as extraction solvent. Additionally, in all cases, values obtained for A. dioica extracts were superior. In a study performed by Albayrak et al. [28] on Helichrysum sp. from Turkey, a TPC value of $115.76 \mathrm{mg} \mathrm{GAE} / \mathrm{g}$ of plant extract for methanolic extracts of H. arenarium subsp. aucheri was obtained. Moreover, Grădinaru et al. [22] found a total phenolic content value of $160.17 \mathrm{mg} \mathrm{GAE} / \mathrm{g}$ d.w. for a methanolic extract of H. arenarium collected from Eastern part of Romania. However, these results are rather hard to be compared with the ones presented herein, due to different extraction solvents, as well as different ways of expressing values.

Regarding the total flavonoid content, the highest value was obtained for the methanolic extract of H. arenarium (36.41 $\mathrm{mg} \mathrm{QE/g} \mathrm{d.w.),} \mathrm{while} \mathrm{the} \mathrm{lowest} \mathrm{values} \mathrm{were} \mathrm{registered} \mathrm{for} \mathrm{the} \mathrm{ethanolic} \mathrm{extract} \mathrm{of}$ 
A. dioica (11.95 mg QE/g d.w.) (Figure 3). As a peculiarity, despite different extractive solvents, the TFC values obtained for $H$. arenarium extracts were higher than the ones obtained for $A$. dioica extracts.

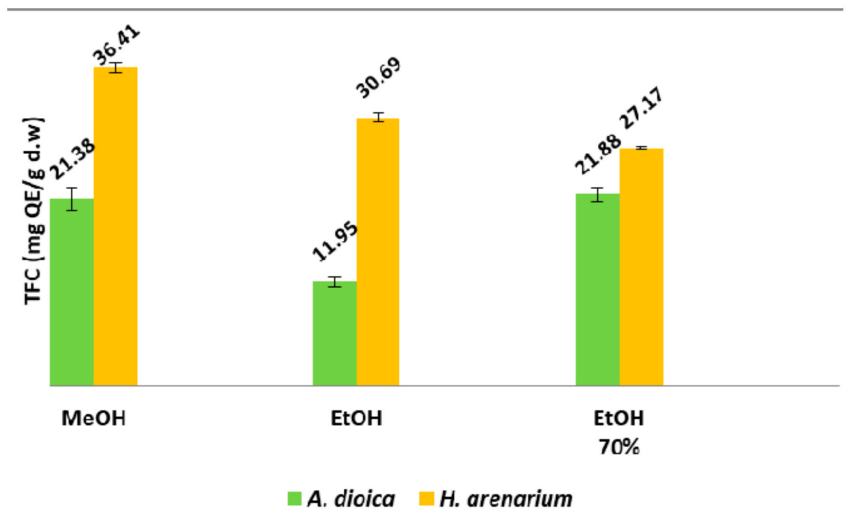

Figure 3. Total flavonoid content (TFC) of H. arenarium and A. dioica species.

\subsection{Assay of the Antimicrobial Activity}

The antibacterial and antifungal activities of $H$. arenarium and A. dioica species were tested against a panel of five bacteria and five fungi, selected based on their relevance for public health. Additionally, up-to-date information about the antibacterial and antifungal activities of extracts from $H$. arenarium and A. dioica collected from Romania is limited. Staphylococcus aureus and Escherichia coli were the most sensitive strains towards $70 \%(v / v)$ ethanolic extract of $A$. dioica and methanolic extracts of $H$. arenarium and ethanolic extracts of $H$. arenarium, with similar values of MIC $-7.81 \mathrm{mg} / \mathrm{mL}$ and MBC-15.62 mg/mL (Tables 6 and 7).

Table 6. Minimum inhibitory concentration-MIC $(\mathrm{mg} / \mathrm{mL})$ of H. arenarium and A. dioica extracts and standard antibiotic.

\begin{tabular}{|c|c|c|c|c|c|c|}
\hline \multicolumn{2}{|c|}{ Samples } & $\begin{array}{c}\text { Staphylococcus } \\
\text { aureus } \\
\text { (ATCC 49444) }\end{array}$ & $\begin{array}{l}\text { Bacillus cereus } \\
\text { (ATCC 11778) }\end{array}$ & $\begin{array}{c}\text { Listeria } \\
\text { monocytogenes } \\
\text { (ATCC 19114) }\end{array}$ & $\begin{array}{c}\text { Salmonella } \\
\text { typhimurium } \\
(\text { ATCC 14028) }\end{array}$ & $\begin{array}{l}\text { Escherichia coli } \\
\text { (ATCC 25922) }\end{array}$ \\
\hline \multirow{3}{*}{ A. dioica } & $\mathrm{MeOH}$ & 62.5 & 62.5 & 31.25 & 31.25 & 15.62 \\
\hline & EtOH & 15.62 & 31.25 & 62.5 & 31.25 & 15.62 \\
\hline & EtOH 70\% & 7.81 & 31.25 & 31.25 & 31.25 & 7.81 \\
\hline \multirow{3}{*}{ H. arenarium } & $\mathrm{MeOH}$ & 7.81 & 31.25 & 31.25 & 62.5 & 7.81 \\
\hline & EtOH & 7.81 & 15.62 & 15.62 & 62.5 & 7.81 \\
\hline & EtOH 70\% & 15.62 & 15.62 & 31.25 & 31.25 & 7.81 \\
\hline \multicolumn{2}{|c|}{ Streptomycin } & 0.03 & 0.015 & 0.015 & 0.06 & 0.12 \\
\hline
\end{tabular}

Table 7. Minimum bactericidal concentration-MBC $(\mathrm{mg} / \mathrm{mL})$ of $H$. arenarium and $A$. dioica extracts and standard antibiotic.

\begin{tabular}{|c|c|c|c|c|c|c|}
\hline \multicolumn{2}{|c|}{ Samples } & $\begin{array}{c}\text { Staphylococcus } \\
\text { aureus } \\
\text { (ATCC 49444) }\end{array}$ & $\begin{array}{l}\text { Bacillus cereus } \\
\text { (ATCC 11778) }\end{array}$ & $\begin{array}{c}\text { Listeria } \\
\text { monocytogenes } \\
\text { (ATCC 19114) }\end{array}$ & $\begin{array}{c}\text { Salmonella } \\
\text { typhimurium } \\
\text { (ATCC 14028) }\end{array}$ & $\begin{array}{c}\text { Escherichia coli } \\
\text { (ATCC 25922) }\end{array}$ \\
\hline \multirow{3}{*}{ A.dioica } & $\mathrm{MeOH}$ & 125 & 125 & 62.5 & 62.5 & 31.25 \\
\hline & EtOH & 31.25 & 62.5 & 125 & 62.5 & 31.25 \\
\hline & EtOH 70\% & 15.62 & 62.5 & 62.5 & 62.5 & 15.62 \\
\hline \multirow{3}{*}{ H. arenarium } & $\mathrm{MeOH}$ & 15.62 & 62.5 & 62.5 & 125 & 15.62 \\
\hline & EtOH & 15.62 & 31.25 & 31.25 & 125 & 15.62 \\
\hline & EtOH 70\% & 31.25 & 31.25 & 62.5 & 62.5 & 15.62 \\
\hline \multicolumn{2}{|c|}{ Streptomycin } & 0.06 & 0.030 & 0.030 & 0.12 & 0.24 \\
\hline
\end{tabular}

Additionally, $70 \%(v / v)$ ethanolic extracts of $H$. arenarium showed a good antibacterial activity on the E. coli strain (MIC-7.81 mg/mL, and MBC-15.62 mg/mL). Nonetheless, the most resistant 
strain was Listeria monocytogenes, showing the highest results for both $\mathrm{MIC}-62.5 \mathrm{mg} / \mathrm{mL}$ and $\mathrm{MBC}-125 \mathrm{mg} / \mathrm{mL}$ values for ethanolic extracts of $A$. dioica. The antibacterial activity of phenolic compounds has been demonstrated in various studies [29]. As a result, the antibacterial activity of $H$. arenarium and $A$. dioica extracts could be attributed at least in part to phenolic compounds.

Concerning the antifungal activity of the samples (Table 8), Penicillium fumiculosum exhibited the highest sensitivity to ethanolic extracts of $H$. arenarium and $70 \%(v / v)$ ethanolic extracts of $H$. arenarium with MIC $-7.81 \mathrm{mg} / \mathrm{mL}$ and MFC $-15.62 \mathrm{mg} / \mathrm{mL}$. Moreover, the strain of Candida albicans showed a similar susceptibility to the inhibitory MIC $-7.81 \mathrm{mg} / \mathrm{mL}$ and fungicidal $\mathrm{MFC}-15.62 \mathrm{mg} / \mathrm{mL}$ of $70 \%(v / v)$ effects of ethanolic extracts of $H$. arenarium. Additionally, the most resistant fungal strains were Aspergillus flavus and Aspergillus niger towards the methanolic extracts of $A$. dioica with MIC $-125 \mathrm{mg} / \mathrm{mL}$ and MFC $-250 \mathrm{mg} / \mathrm{mL}$, respectively. Overall, $H$. arenarium extracts presented a superior antifungal activity than $A$. dioica samples, for all tested fungal strains. The antimicrobial activity of the studied Helichrysum and Antennaria species could be at least partially ascribed to the presence of chlorogenic acid. According to Lou et al. [30], chlorogenic acid induced lethal effect on both Gram-positive and Gram-negative bacteria by provoking irreversible permeability changes in the cell membrane, causing the cells to lose the ability to maintain membrane potential.

Table 8. Minimum inhibitory concentration MIC $(\mathrm{mg} / \mathrm{mL})$ and minimum fungicidal concentration MFC (mg/mL) of H. arenarium and A. dioica extracts and standard antibiotic.

\begin{tabular}{|c|c|c|c|c|c|c|c|c|c|c|c|c|c|c|}
\hline & \multicolumn{6}{|c|}{ A. dioica } & \multicolumn{6}{|c|}{ H. arenarium } & \multirow{2}{*}{\multicolumn{2}{|c|}{ Fluconazole }} \\
\hline & \multicolumn{2}{|c|}{$\mathrm{MeOH}$} & \multicolumn{2}{|c|}{ EtOH } & \multicolumn{2}{|c|}{ EtOH 70\% } & \multicolumn{2}{|c|}{$\mathrm{MeOH}$} & \multicolumn{2}{|c|}{ EtOH } & \multicolumn{2}{|c|}{ EtOH 70\% } & & \\
\hline & MIC & MFC & MIC & MFC & MIC & MFC & MIC & MFC & MIC & MFC & MIC & MFC & MIC & MFC \\
\hline Aspergillus flavus & 125 & 250 & 62.5 & 125 & 62.5 & 125 & 62.5 & 125 & 31.25 & 62.5 & 31.25 & 62.5 & 0.15 & 0.3 \\
\hline Aspergillus niger & 125 & 250 & 62.5 & 125 & 31.25 & 62.5 & 62.5 & 125 & 31.25 & 62.5 & 31.25 & 62.5 & 0.15 & 0.3 \\
\hline Candida albicans & 31.25 & 62.5 & 31.25 & 62.5 & 15.62 & 31.25 & 31.25 & 62.5 & 15.62 & 31.25 & 7.81 & 15.62 & 0.10 & 0.2 \\
\hline Candida parapsilosis & 62.5 & 125 & 31.25 & 62.5 & 31.25 & 62.5 & 31.25 & 62.5 & 15.62 & 31.25 & 15.62 & 31.25 & 0.10 & 0.2 \\
\hline Penicillium fumiculosum & 15.62 & 31.25 & 15.62 & 31.25 & 15.62 & 31.25 & 15.62 & 31.25 & 7.81 & 15.62 & 7.81 & 15.62 & 0.15 & 0.3 \\
\hline
\end{tabular}

\section{Materials and Methods}

\subsection{Plant Material}

Flowers of H. arenarium were collected from Botoșani county (North Eastern Romania), while flowers of $A$. dioica were collected from Suceava county, (North Eastern Romania). The species were identified by Dr. Ramona Păltinean, and voucher specimens were deposited in the Herbarium of the Department of Pharmaceutical Botany, Faculty of Pharmacy, "Iuliu Hațieganu" University of Medicine and Pharmacy, Cluj-Napoca, Romania (H. arenarium-Voucher No. 143.17.3.1 and A. dioica- Voucher No. 143.14.1.1).

\subsection{Extraction Procedure}

Dried flowers belonging to the two species were ground to a fine powder. This powder (1.00 g) was mixed with the appropriate solvent $(20.00 \mathrm{~mL})$ in a round-bottom flask and stirred for $20 \mathrm{~min}$ at $600 \mathrm{rpm}$ on a mechanical stirrer. The solutions were then extracted by sonication for $30 \mathrm{~min}$, at $70{ }^{\circ} \mathrm{C}$, using as solvents methanol (99.98\%), ethanol (96\%) and 70\% v/v ethanol in water. Subsequently, extracts were filtered and evaporated to dryness under reduced pressure, using a rotary evaporator. The crude extracts were weighed and stored in the refrigerator until they were analyzed. All analyses were performed in triplicate on the three types of extracts and the results were presented as mean \pm SD.

In order to obtain more accurate data on flavonoid glycosides and aglycones concentration, each sample was analyzed before and after acid hydrolysis. Extractive solution $(2.00 \mathrm{~mL})$ was treated with $2 \mathrm{M}$ hydrochloric acid $(2.00 \mathrm{~mL})$ and a $100 \mathrm{mg} / \mathrm{mL}$ ascorbic acid solution $(0.20 \mathrm{~mL})$. The mixtures were heated at $80^{\circ} \mathrm{C}$ on a water bath for $30 \mathrm{~min}$, ultrasonicated for $15 \mathrm{~min}$, and re-heated for another $30 \mathrm{~min}$ at $80{ }^{\circ} \mathrm{C}$. During the heating, $1.00 \mathrm{~mL}$ of each solvent was added to the extraction mixture every $10 \mathrm{~min}$, 
in order to ensure a constant volume. The mixtures were centrifuged at $4000 \mathrm{rpm}$ and the solutions were diluted with distilled water in a $10.00 \mathrm{~mL}$ volumetric flask and filtered through a $0.45 \mu \mathrm{m}$ filter before injection [31]. For the antimicrobial activity, the obtained extracts were evaporated to dryness under reduced pressure and re-suspended in bi-distilled water.

\subsection{Chemicals}

References used for the HPLC-MS analysis were purchased from Sigma Aldrich (St. Louis, MO, USA): Chlorogenic acid, p-coumaric acid, caffeic acid, rutin, apigenin, quercetin, isoquercitrin, quercitrin, hyperoside, kaempferol, myricetol, and fisetin, Roth (Karlsruhe, Germany): Ferulic acid, sinapic acid, gentisic acid, gallic acid, patuletin, luteolin or from Dalton (Toronto, ON, Canada): cichoric acid, caftaric acid. HPLC grade solvents, analytical grade acids used for mobile phases and Folin-Ciocâlteu reagent were purchased from Merck (Darmstadt, Germany), together with sodium carbonate, dipotassium hydrogen phosphate, potassium dihydrogen phosphate and aluminium chloride used for antioxidant assays. ABTS (2,2'-azino-bis(3-ethylbenzothiazoline-6-sulfonic acid) diammonium salt) $\geq 98 \%$ purity, potassium peroxodisulfate ( $\geq 99 \%$ purity), DPPH, and Trolox (6-hydroxy-2,5,7,8-tetramethylchromane-2-carboxylic acid; $\geq 97 \%$ purity) also used in antioxidant tests were purchased from Sigma Aldrich (Schnelldorf, Germany). Gallic acid monohydrate (99.5\%) was purchased from Serva, (Heidelberg, Germany).

\subsection{HPLC-MS Analysis}

\subsubsection{Apparatus and Chromatographic Conditions}

Polyphenols, methoxylated flavones and phytosterols were analyzed and quantified using an HPLC-MS method. The apparatus consisted in an 1100 HPLC Series Agilent Technologies system (Agilent, Santa Clara, CA, USA), equipped with a G1322A degasser, G13311A binary gradient pump, column thermostat, G1313A autosampler and G1316A UV detector. The HPLC system was coupled with an Agilent 1100 mass spectrometer (LC/MSD Ion Trap VL). The chromatographic data were processed using ChemStation and DataAnalysis software from Agilent [25,32-34].

\subsubsection{HPLC-MS Analysis of Phenolic Compounds}

Analysis of phenols was carried out on by injecting $5 \mu \mathrm{L}$ of the flowers extracts of H. arenarium and A. dioica on a Zorbax SB-C18 reverse-phase analytical column $(100 \times 3.0 \mathrm{~mm}$ i.d., $3.5 \mu \mathrm{m}$ particles $)$ and separation of compounds was performed using as a mobile phase a mixture of methanol and acetic acid $0.1 \% v / v$. The flow rate was set at $1 \mathrm{~mL} / \mathrm{min}$ and working temperature was $48{ }^{\circ} \mathrm{C}$. The binary gradient that allowed the elution of compounds started with $5 \%$ methanol in a linear mode and ended with $42 \%$ methanol, for $35 \mathrm{~min}$. The last $3 \mathrm{~min}$ of the gradient were set at $42 \%$ methanol. Detection of the compounds was performed on UV, at $330 \mathrm{~nm}$ until $17.5 \mathrm{~min}$ and at $370 \mathrm{~nm}$ until the end of the analysis time. The MS was also used for detection of compounds and was operated in a negative mode, using an electrospray ion source. Using these conditions, all polyphenols could be eluted in less than 40 min (Table 9) [25,32-34].

The specific mass spectra of each polyphenol were recorded in a library and the MS traces/spectra of the compounds that were found in samples were compared with spectra existing in the library. Qualitative analysis of polyphenols was performed based on the MS signal, used for identification of compounds; only compounds identified on basis of their MS spectra were further quantified using the UV signal. Quantitative analyses were performed using the external standard method, with calibration curves of 5 points, ranging between $0.5-50 \mu \mathrm{g} / \mathrm{mL}$, having a good linearity $\left(R^{2}>0.999\right)$. Limit of quantification in this method was $0.5 \mu \mathrm{g} / \mathrm{mL}$, and the limit of detection was $0.1 \mu \mathrm{g} / \mathrm{mL}[25,32-34]$. 
Table 9. Retention times (RT) and values of $m / z$ for the tested polyphenolic compounds.

\begin{tabular}{cccc}
\hline Peak No. & Phenolic Compounds & $\mathbf{m} / \boldsymbol{z}$ & $\mathbf{R T} \pm \mathbf{S D}(\mathbf{m i n})$ \\
\hline $\mathbf{1}$ & Caftaric acid & 311 & $3.54 \pm 0.05$ \\
$\mathbf{2}$ & Gentisic acid & 179 & $3.52 \pm 0.04$ \\
$\mathbf{3}$ & Caffeic acid & 179 & $5.60 \pm 0.04$ \\
$\mathbf{4}$ & Chlorogenic acid & 353 & $5.62 \pm 0.05$ \\
$\mathbf{5}$ & p-Coumaric acid & 163 & $9.48 \pm 0.08$ \\
$\mathbf{6}$ & Ferulic acid & 193 & $12.8 \pm 0.10$ \\
$\mathbf{7}$ & Sinapic acid & 223 & $15.00 \pm 0.10$ \\
$\mathbf{8}$ & Cichoric acid & 473 & $15.96 \pm 0.13$ \\
$\mathbf{9}$ & Hyperoside & 463 & $18.60 \pm 0.12$ \\
$\mathbf{1 0}$ & Isoquercitrin & 463 & $19.60 \pm 0.10$ \\
$\mathbf{1 1}$ & Rutin & 609 & $20.20 \pm 0.15$ \\
$\mathbf{1 2}$ & Myricetin & 317 & $21.13 \pm 0.12$ \\
$\mathbf{1 3}$ & Fisetin & 285 & $22.91 \pm 0.15$ \\
$\mathbf{1 4}$ & Quercitrin & 447 & $23.64 \pm 0.13$ \\
$\mathbf{1 5}$ & Quercetin & 301 & $26.80 \pm 0.15$ \\
$\mathbf{1 6}$ & Patuletin & 331 & $29.41 \pm 0.12$ \\
$\mathbf{1 7}$ & Luteolin & 285 & $29.10 \pm 0.19$ \\
$\mathbf{1 8}$ & Kaempferol & 285 & $32.48 \pm 0.17$ \\
$\mathbf{1 9}$ & Apigenin & 279 & $33.10 \pm 0.15$ \\
\hline
\end{tabular}

\subsubsection{HPLC-MS Analysis of Methoxylated Flavones}

Analysis of methoxylated flavones was carried out on the same HPLC instrument, using the same analytical column. Mobile phase also consisted in the mixture of $0.1 \%(v / v)$ acetic acid and methanol, but ratios of solvents were changed in order to better perform the separation of compounds. Total duration of the method was less than $10 \mathrm{~min}$ and gradient began with $45 \%$ methanol and ended at $50 \%$ methanol, with a flow rate of $0.9 \mathrm{~mL} / \mathrm{min}$. Injection volume was $5 \mu \mathrm{L}$ and temperature was set at $48^{\circ} \mathrm{C}$. Detection was performed on the same MS/MS system, using an electrospray ionization (ESI) source, in negative mode. Conditions used for detection were set as following: nebulizer pressure at $60 \mathrm{psi}$, gas (nitrogen) temperature at $325^{\circ} \mathrm{C}$ with a flow rate of $12 \mathrm{~L} / \mathrm{min}$, and capillary voltage $+2500 \mathrm{~V}$. Specific fragments were monitored. Identification was achieved by comparison of retention times and mass spectra for the existing references (Table 10) and compounds identified in samples. Parent ions were detected as forms of the molecules, which have lost a proton. The multiple reaction monitoring mode was used in order to avoid background interferences [33,34].

Table 10. Retention times (RT) and specific ions of the tested methoxylated flavones.

\begin{tabular}{ccccc}
\hline Compound & Retention Time $(\mathbf{m i n})$ & $\mathbf{M}$ & $\mathbf{M}-\mathbf{H}^{-}$ & Ions/Fragments \\
\hline Jaceosidin & 2.9 & 330.3 & 329.3 & 314 \\
Hispidulin & 4.2 & 300.2 & 299.2 & 284 \\
Eupalitin & 7.05 & 344.3 & 343.3 & 328 \\
Eupatorin & 7.6 & 344.3 & 343.3 & 328 \\
Casticin & 8.05 & 374.3 & 373.3 & 358 \\
Acacetin & 9.8 & 284.3 & 283.3 & 268 \\
\hline
\end{tabular}

\subsubsection{HPLC-MS Analysis of Phytosterols}

Conditions for the analysis of phytosterols were also slightly different from the ones described in the analysis of polyphenols and methoxylated flavones. Same apparatus was used for the separation of compounds. Chromatographic analytical column was the same, but elution of compounds was performed in an isocratic mode, in a mixture of 10:90 $(v / v)$ of methanol and acetonitrile. Flow rate was set at $1 \mathrm{~mL} / \mathrm{min}$, chromatographic system was operated at $40{ }^{\circ} \mathrm{C}$ and the injection volume was 
$5 \mu \mathrm{L}$. For detection of compounds, the same mass spectrometer was used, with an atmospheric pressure chemical ionization (APCI) interface, in a positive mode. Conditions were set as following: gas temperature (nitrogen) $325^{\circ} \mathrm{C}$ at a flow rate of $7 \mathrm{~L} / \mathrm{min}$, nebulizer pressure 60 psi and capillary voltage $-4000 \mathrm{~V}$. Identification of compounds was performed on the same basis as the one performed for methoxylated flavones, using the multiple reactions monitoring analysis model (Table 11) [32].

Table 11. Retention times (RT) and specific ions of the phytosterols.

\begin{tabular}{ccccc}
\hline Phytosterol & Retention Time (min) & $\mathbf{M}$ & $\mathbf{M}-\mathbf{H}_{\mathbf{2}} \mathbf{O}$ & $\mathbf{M}-\mathbf{H}_{\mathbf{2}} \mathbf{O}+\mathbf{H}^{+}$ \\
\hline Ergosterol & 2.6 & 396 & 378 & 379 \\
Brassicasterol & 3.3 & 398 & 380 & 381 \\
Stigmasterol & 4.0 & 412 & 394 & 395 \\
Campesterol & 4.0 & 400 & 382 & 383 \\
Sitosterol & 4.6 & 414 & 396 & 397 \\
\hline
\end{tabular}

\subsection{Determination of Total Phenolic Content}

The TPC was determined using the Folin-Ciocâlteu method. For a high throughput of samples, a SPECTROstar Nano Multi-Detection Microplate Reader with 96-well plates (BMG Labtech, Ortenberg, Germany) was used. Briefly, a mixture solution consisting of $20 \mu \mathrm{L}$ of extract, $100 \mu \mathrm{L}$ of Folin-Ciocâlteu reagent and $80 \mu \mathrm{L}$ of sodium carbonate $\left(\mathrm{Na}_{2} \mathrm{CO}_{3}, 7.5 \% w / v\right)$ was homogenized and incubated at room temperature in the dark for $30 \mathrm{~min}$. Afterwards, the absorbance of the samples was measured at $760 \mathrm{~nm}$. Gallic acid was used as a reference standard, and the TPC was expressed as gallic acid equivalents (GAE) in $\mathrm{mg} / \mathrm{g}$ dry weight (d.w.) of plant material $[35,36]$.

\subsection{Determination of Total Flavonoid Content}

The total flavonoid content (TFC) was calculated and expressed as quercetin equivalents using a method previously described by Mocan et al. [37,38]. Briefly, a $100 \mu \mathrm{L}$ aliquot of $2 \% \mathrm{AlCl}_{3}$ aqueous solution was mixed with $100 \mu \mathrm{L}$ of sample. After an incubation time of $15 \mathrm{~min}$, the absorbance of the sample was measured at $420 \mathrm{~nm}$. Quercetin was used as a reference standard, and the TFC was expressed as quercetin equivalents $(\mathrm{QE}) \mathrm{in} \mathrm{mg} / \mathrm{g}$ dry weight (d.w.) of plant material.

\subsection{Antioxidant Activity Assays}

\subsubsection{TEAC Assay}

The TEAC of the different Helichrysum and Antennaria extracts against the stable synthetic ABTS radical cation was tested using the method described by Martinez et al. [39] and Savran et al. [40]. A Trolox calibration curve was plotted as a function of the percentage of ABTS radical cation scavenging activity, and the results were expressed as milligrams of trolox equivalents (TE) per milliliter of herbal extract (mg TE/mL).

\subsubsection{DPPH Assay}

The antioxidant capacity of the investigated samples against the DPPH radical was tested using the method previously described by Martins et al. and Mocan et al. [41,42]. A Trolox calibration curve was plotted as a function of DPPH consumption, and the results were expressed as milligrams of trolox equivalents (TE) per milliliter of herbal extract $(\mathrm{mg} \mathrm{TE} / \mathrm{mL})$.

\subsection{Assay of Antimicrobial Activity}

\subsubsection{Bacteria and Culture Conditions}

For this bioassay, five aerobic bacterial strains were used, Staphylococcus aureus (ATCC 49444), Bacillus cereus (ATCC 11778), Listeria monocytogenes (ATCC 19114), Salmonella typhimurium (ATCC 14028), 
and Escherichia coli (ATCC 25922). All of the tested microorganisms were obtained from the Laboratory of Food Biotechnology, Life Sciences Institute, University of Agricultural Sciences and Veterinary Medicine, Cluj Napoca, Romania. The bacteria were cultured on Muller-Hinton Agar and stored at $4{ }^{\circ} \mathrm{C}$ and subcultured once a month.

The modified microdilution technique was used to evaluate antimicrobial activity as previously reported by Mocan et al. [29,38]. Bacterial species were cultured overnight at $37^{\circ} \mathrm{C}$ in Tryptic Soy Broth (TSB) medium. The bacterial cell suspensions were adjusted with sterile saline to a concentration of approximately $3 \times 10^{5} \mathrm{CFU} / \mathrm{mL}$ in a final volume of $100 \mu \mathrm{L}$ per well. The inoculum was stored at $+4{ }^{\circ} \mathrm{C}$ for further use. Dilutions of the inoculum were cultured on solid Muller-Hinton (MH) for bacteria to verify the absence of contamination and to check the validity of the inoculum. Determinations of minimum inhibitory concentrations (MICs) were performed by a serial dilution technique using 96-well microtitre plates. The concentration range of extracts was $1000-0.03 \mathrm{mg} / \mathrm{mL}$. Different solvent dilutions of ethanol: methanol extracts were carried out over the wells containing $100 \mu \mathrm{L}$ of Tryptic Soy Broth (TSB) and afterwards, $10 \mu \mathrm{L}$ of inoculum was added to all the wells. The microplates were incubated for $24-48 \mathrm{~h}$ at $37^{\circ} \mathrm{C}$. The MIC of the samples was detected following the addition of $20 \mu \mathrm{L}(0.2 \mathrm{mg} / \mathrm{mL})$ of resazurin solution to each well, and the plates were incubated $2 \mathrm{~h}$ at $37^{\circ} \mathrm{C}$. A change from blue to pink indicates reduction of resazurin and, therefore, bacterial growth. The MIC was defined as the lowest drug concentration that prevented this color change. The minimum bactericidal concentrations (MBCs) were determined by serial subcultivation of a $2 \mu \mathrm{L}$ into microtitre plates containing $100 \mu \mathrm{L}$ of broth per well and further incubation for $48 \mathrm{~h}$ at $37^{\circ} \mathrm{C}$. The lowest concentration with no visible growth was defined as MBC, indicating $99.5 \%$ killing of the original inoculum. Streptomycin (Sigma $\mathrm{P} 7794)(0.05-3 \mathrm{mg} / \mathrm{mL})$ was used as positive control. Water was used as negative control.

\subsubsection{Antifungal Activity}

To investigate the antifungal activities, the following fungi were used: Aspergillus flavus (ATCC 9643), Aspergillus niger (ATCC 6275), Candida albicans (ATCC 10231), Candida parapsilosis (ATCC 22019) and Penicillium funiculosum (ATCC 56755). These fungi were obtained from the Laboratory of Food Biotechnology, Life Sciences Institute, University of Agricultural Sciences and Veterinary Medicine, Cluj-Napoca, Romania. Cultures were maintained on malt agar at $4{ }^{\circ} \mathrm{C}$ and subcultured every month. Spore suspension $\left(1.0 \times 10^{5}\right)$ was obtained by washing agar plates with sterile solution containing $(0.85 \%$ saline, $0.1 \%$ Tween $80(v / v)$, then added to each well to a final volume of $100 \mu \mathrm{L}$. Inocula were screened for contamination by culturing on a solid medium. The minimum inhibitory (MIC) and minimum fungicidal (MFC) concentrations assays were performed using the microdilution method by preparing a serial of dilutions in 96-well microtiter plates. The extracts were diluted in $0.85 \%$ saline $(10 \mathrm{mg} / \mathrm{mL})$, then added to microplates containing Broth Malt medium with inoculum and incubated for $72 \mathrm{~h}$ at $28^{\circ} \mathrm{C}$ on a rotary shaker. The lowest concentrations without visible growth (at the binocular microscope) were defined as minimal inhibitory concentrations (MICs). The fungicidal concentrations (MFCs) were determined by serial sub-cultivation of $2 \mu \mathrm{L}$ of tested extracts dissolved in medium and inoculated for $72 \mathrm{~h}$, into microtiter plates containing $100 \mu \mathrm{L}$ of broth per well and further incubation $72 \mathrm{~h}$ at $28^{\circ} \mathrm{C}$. The lowest concentration with no visible growth was defined as MFC indicating $99.5 \%$ killing of the original inoculum. The fungicide fluconazole was used as positive control $(1-3500 \mu \mathrm{g} / \mathrm{mL})$. All experiments were performed in duplicate and repeated thrice [29].

\subsection{Statistical Analysis}

The samples have been analyzed in triplicate; the average and the relative SD have been calculated using the Excel software package (Microsoft, Redmond, WA, USA). 


\section{Conclusions}

An in-depth chemical composition of several classes of bioactive compounds revealed that traditionally used Romanian $H$. arenarium and A. dioica represent important sources of bioactive compounds with potent in vitro activities. According to the obtained results, H. arenarium and A. dioica $70 \% \mathrm{EtOH}$ extracts represent important sources of chlorogenic acid and flavonoids. Moreover, the biological properties of these species indicate their potential usage in oxidative stress related disorders. Particularly, even though the investigated species are traditionally used as herbal remedies with antimicrobial potential, the results obtained for the current investigated samples are modest. However, further studies are necessary in order to elucidate the mechanisms of in vivo antioxidant and microbial inhibition action, bioavailability and involved metabolic pathways.

Acknowledgments: This work is published within/under the internal grant No.: 4995/24/08.03.2016, financed by "Iuliu Hatieganu" University of Medicine and Pharmacy, Department of Pharmaceutical Botany, Cluj-Napoca, Romania.

Author Contributions: Important contributions to design and to preparing the manuscript: M.B., R.P., A.M., I.I., G.C. Phytochemical screening was performed by L.V., A-M.G., M.B. Contributed to antioxidant and antimicrobial experiments: A.M., D.C.V., and M.B. Analysis of the experimental data: A.M., I.I., M.B., D.C.V., R.P., O.C. and L.V. Revising it critically for important intellectual content: R.P., I.I., A.M., O.C. and G.C. All authors helped in preparing the paper and approved the final version.

Conflicts of Interest: The authors declare no conflict of interest.

\section{References}

1. Erbar, C.; Leins, P. Diversity of styles and mechanisms of secondary pollen presentation in basal Asteraceae-New insights in phylogeny and function. Flora Morphol. Distrib. Funct. Ecol. Plants 2015, 217, 109-130. [CrossRef]

2. Bohm, B.A.; Stuessy, T.F. Introduction to the Sunflower Family. In Flavonoids of the Sunflower Family (Asteraceae); Springer-Verlag/Wien: New York, NY, USA, 2001; p. 1. ISBN 3211834796.

3. García-Herrera, P.; Sánchez-Mata, M.C.; Cámara, M.; Fernández-Ruiz, V.; Díez-Marqués, C.; Molina, M.; Tardío, J. Nutrient composition of six wild edible Mediterranean Asteraceae plants of dietary interest. J. Food Compos. Anal. 2014, 34, 163-170. [CrossRef]

4. Bessada, S.M. F.; Barreira, J.C. M.; Oliveira, M.B. P.P. Asteraceae species with most prominent bioactivity and their potential applications: A review. Ind. Crops Prod. 2015, 76, 604-615. [CrossRef]

5. Abad, M.J.; Bedoya, L.M.; Bermejo, P. Essential Oils from the Asteraceae Family Active against Multidrug-Resistant Bacteria. In Fighting Multidrug Resistance with Herbal Extracts, Essential Oils and their Components; Academic Press: San Diego, CA, USA, 2013; pp. 205-219. ISBN 9780123985392.

6. The Euro+Med PlantBase. The Information Resource for Euro-Mediterranean Plant Diversity; Università degli Studi di Palermo: Palermo, Italy, 2011.

7. Bayer, R.J.; Puttock, C.F.; Kelchner, S.A. Phylogeny of South African Gnaphalieae (Asteraceae) based on two noncoding chloroplast sequences. Am. J. Bot. 87, 259-272. [CrossRef]

8. Tutin, T.G.; Burges, N.A.; Chater, A.O.; Edmonson, J.R.; Heywood, V.H.; Moore, D.M.; Valentine, D.H.; Walters, S.M.; Webb, D.A. Flora Europaea, 2nd ed.; Cambridge University Press: Cambridge, UK, 2010.

9. Săvulescu, T. Flora Republicii Populare Romîne; Editura Academiei Republicii Populare Romînia: Bucuresti, Romînia, 1964.

10. Freire, S.E.; Chemisquy, M.A.; Anderberg, A.A.; Beck, S.G.; Meneses, R.I.; Loeuille, B.; Urtubey, E. The Lucilia group (Asteraceae, Gnaphalieae): Phylogenetic and taxonomic considerations based on molecular and morphological evidence. Plant Syst. Evol. 2015, 301, 1227-1248. [CrossRef]

11. Galbany-Casals, M.; Garcia-Jacas, N.; Saez, L.; Benedi, C.; Susanna, A. Phylogeny, Biogeography, and Character Evolution in Mediterranean, Asiatic, and Macaronesian Helichrysum (Asteraceae, Gnaphalieae) Inferred From Nuclear Phylogenetic Analyses. Int. J. Plant Sci. 2009, 170, 365-380. [CrossRef]

12. Lourens, A.C.U.; Viljoen, A.M.; van Heerden, F.R. South African Helichrysum species: A review of the traditional uses, biological activity and phytochemistry. J. Ethnopharmacol. 2008, 119, 630-652. [CrossRef] [PubMed] 
13. Semeniv, D.V.; Belik, G.V. The experience of Antennaria dioica application in folk medicine and prospects of this plant use for creation of new phytohemostatics. Ukranian Biopharm. J. 2016, 6, 37-41.

14. Shikov, A.N.; Pozharitskaya, O.N.; Makarov, V.G.; Wagner, H.; Verpoorte, R.; Heinrich, M. Medicinal Plants of the Russian Pharmacopoeia; Their history and applications. J. Ethnopharmacol. 2014, 154, 481-536. [CrossRef] [PubMed]

15. Mericli, A.H. Constituents of Antennaria dioica. J. Nat. Prod 1983, 46, 941-941. [CrossRef]

16. Drăgulescu, R. Representations of the fire in Romanian phytonymy. In Multicultural Representations. Literature and Discourse as Forms of Dialogue; Iulian, B., Cornel, S., Eds.; Arhipelag XXI Press: Tîrgu Mureș, Romania, 2016; pp. 16-17. ISBN 9786068624167.

17. Coady, Y.; Boylan, F. Ethnopharmacology in Ireland: An overview. Braz. J. Pharmacogn. 2014, 24, $197-205$. [CrossRef]

18. Onaran, M.; Orhan, N.; Farahvash, A.; Ekin, H.N.; Kocabiyik, M.; Gönül, I.I.; Șen, I.; Aslan, M. Successful treatment of sodium oxalate induced urolithiasis with Helichrysum flowers. J. Ethnopharmacol. 2016, 186, 322-328. [CrossRef] [PubMed]

19. Czinner, E.; Hagymási, K.; Blázovics, A.; Kéry, Á.; Szoke, É.; Lemberkovics, É. In vitro antioxidant properties of Helichrysum arenarium (L.) Moench. J. Ethnopharmacol. 2000, 73, 437-443. [CrossRef]

20. Mao, Z.; Gan, C.; Zhu, J.; Ma, N.; Wu, L.; Wang, L.; Wang, X. Anti-atherosclerotic activities of flavonoids from the flowers of Helichrysum arenarium L. MOENCH through the pathway of anti-inflammation. Bioorg. Med. Chem. Lett. 2017, 27, 2812-2817. [CrossRef] [PubMed]

21. Albayrak, S.; Aksoy, A.; Sagdic, O.; Budak, U. Phenolic compounds and antioxidant and antimicrobial properties of Helichrysum species collected from eastern Anatolia, Turkey. Turk. J. Biol. 2010, 34, 463-473. [CrossRef]

22. Grădinaru, A.C.; Silion, M.; Trifan, A.; Miron, A.; Aprotosoaie, A.C. Helichrysum arenarium subsp. arenarium: Phenolic composition and antibacterial activity against lower respiratory tract pathogens. Nat. Prod. Res. 2014, 28, 2076-2080. [CrossRef] [PubMed]

23. Grinev, V.S.; Shirokov, A.A.; Navolokin, N.A.; Polukonova, N.V.; Kurchatova, M.N.; Durnova, N.A.; Bucharskaya, A.B.; Maslyakova, G.N. Polyphenolic compounds of a new biologically active extract from immortelle sandy flowers (Helichrysum arenarium (L.) Moench.). Russ. J. Bioorg. Chem. 2016, 42, 770-776. [CrossRef]

24. Rančić, A.; Soković, M.; Vukojević, J.; Simić, A.; Marin, P.; Duletić-Laušević, S.; Djoković, D. Chemical composition and antimicrobial activities of essential oils of Myrrhis odorata (L.) Scop, Hypericum perforatum (L.) and Helichrysum arenarium (L.) Moench. J. Essent. Oil Res. 2005, 17, 341-345. [CrossRef]

25. Păltinean, R.; Mocan, A.; Vlase, L.; Gheldiu, A.; Crișan, G.; Ielciu, I.; Voștinaru, O.; Crișan, O. Evaluation of Polyphenolic Content, Antioxidant and Diuretic Activities of Six Fumaria Species. Molecules 2017, 639. [CrossRef] [PubMed]

26. Parvu, M.; Toiu, A.; Vlase, L.; Alina Parvu, E. Determination of some polyphenolic compounds from Allium species by HPLC-UV-MS. Nat. Prod. Res. 2010, 24, 1318-1324. [CrossRef] [PubMed]

27. Kiselova, I.; Ivanova, D.; Chervenkov, T.; Gerova, D.; Galunska, B.; Yankova, T. Correlation between the In Vitro Antioxidant Activity and Polyphenol Content of Aqueous Extracts from Bulgarian Herbs. Phytother. Res. 2006, 20, 961-965. [CrossRef] [PubMed]

28. Albayrak, S.; Aksoy, A.; Sagdic, O.; Hamzaoglu, E. Compositions, antioxidant and antimicrobial activities of Helichrysum (Asteraceae) species collected from Turkey. Food Chem. 2010, 119, 114-122. [CrossRef]

29. Mocan, A.; Zengin, G.; Simirgiotis, M.; Schafberg, M.; Mollica, A.; Vodnar, D.C.; Crișan, G.; Rohn, S. Functional constituents of wild and cultivated Goji (L. barbarum L.) leaves: Phytochemical characterization, biological profile, and computational studies. J. Enzym. Inhib. Med. Chem. 2017, 32, 153-168. [CrossRef] [PubMed]

30. Lou, Z.; Wang, H.; Zhu, S.; Ma, C.; Wang, Z. Antibacterial activity and mechanism of action of chlorogenic acid. J. Food Sci. 2011, 76, M398-M403. [CrossRef] [PubMed]

31. Vlase, L.; Parvu, M.; Parvu, E.A.; Toiu, A. Phytochemical analysis of Allium fistulosum L. and A. ursinum L. Dig. J. Nanomater. Biostruct. 2012, 8, 457-467.

32. Mocan, A.; Vodnar, D.; Vlase, L.; Crișan, O.; Gheldiu, A.-M.; Crișan, G. Phytochemical Characterization of Veronica officinalis L., V. teucrium L. and V. orchidea Crantz from Romania and Their Antioxidant and Antimicrobial Properties. Int. J. Mol. Sci. 2015, 16, 21109-21127. [CrossRef] [PubMed] 
33. Mocan, A.; Crişan, G.; Vlase, L.; Ivănescu, B.; Bădărău, A.S.; Arsene, A.L. Phytochemical investigations on four Galium species (Rubiaceae) from Romania. Farmacia 2016, 64, 95-99.

34. Ielciu, I.; Vlase, L.; Frédérich, M.; Hanganu, D.; Păltinean, R.; Cieckiewicz, E.; Olah, N.-K.; Gheldiu, A.-M.; Crişan, G. Polyphenolic profile and biological activities of the leaves and aerial parts of Echinocystis lobata (Michx.) Torr. et A. Gray (Cucurbitaceae). Farmacia 2017, 65, 179-183.

35. Mocan, A.; Schafberg, M.; Crisan, G.; Rohn, S. Determination of lignans and phenolic components of Schisandra chinensis (Turcz.) Baill.using HPLC-ESI-ToF-MS and HPLC-online TEAC: Contribution of individual components to overall antioxidant activity and comparison with traditional antioxidant assay. J. Funct. Food 2016, 24, 579-594. [CrossRef]

36. Mocan, A.; Vlase, L.; Raita, O.; Hanganu, D.; Păltinean, R.; Dezsi, Ş.; Gheldiu, A.-M.; Oprean, R.; Crișan, G. Comparative studies on antioxidant activity and polyphenolic content of Lycium barbarum L. and Lycium chinense Mill. leaves. Pak. J. Pharm. Sci. 2015, 28, 1511-1515. [PubMed]

37. Mocan, A.; Crișan, G.; Vlase, L.; Crișan, O.; Vodnar, D.C.; Raita, O.; Gheldiu, A.; Toiu, A.; Oprean, R.; Tilea, I. Comparative Studies on Polyphenolic Composition, Antioxidant and Antimicrobial Activities of Schisandra chinensis Leaves and Fruits. Molecules 2014, 19, 15162-15179. [CrossRef] [PubMed]

38. Mocan, A.; Vlase, L.; Vodnar, D.C.; Bischin, C.; Hanganu, D.; Gheldiu, A.-M.; Oprean, R.; Silaghi-Dumitrescu, R.; Crișan, G. Polyphenolic Content, Antioxidant and Antimicrobial Activities of Lycium barbarum L. and Lycium chinense Mill. Leaves. Molecules 2014, 19, 10056-10073. [CrossRef] [PubMed]

39. Martinez, E.J. L.; Barrales, P.O.; Zengin, G.; Uysal, S.; Ceylan, R.; Guler, G.O.; Mocan, A.; Aktumsek, A. Lathyrus aureus and Lathyrus pratensis: Characterization of phytochemical profiles by liquid chromatography-mass spectrometry, and evaluation of their enzyme inhibitory and antioxidant activities. RSC Adv. 2016, 6, 88996-89006. [CrossRef]

40. Savran, A.; Zengin, G.; Aktumsek, A.; Mocan, A.; Glamočlija, J.; Ćirić, A.; Soković, M. Phenolic compounds and biological effects of edible Rumex scutatus and Pseudosempervivum sempervivum: Potential sources of natural agents with health benefits. Food Funct. 2016, 7, 3252-3262. [CrossRef] [PubMed]

41. Martins, N.; Barros, L.; Dueñas, M.; Santos-Buelga, C.; Ferreira, I.C. F.R. Characterization of phenolic compounds and antioxidant properties of Glycyrrhiza glabra L. rhizomes and roots. RSC Adv. 2015, 5, 26991-26997. [CrossRef]

42. Mocan, A.; Fernandes, A.; Barros, L.; Crișan, G.; Smiljkovic, M.; Sokovic, M.; Ferreira, I.C.F.R. Chemical composition and bioactive properties of the wild mushroom Polyporus squamosus (Huds.) Fr: A study with samples from Romania. Food Funct. 2018. [CrossRef] [PubMed]

Sample Availability: Samples are not available from the authors.

(C) 2018 by the authors. Licensee MDPI, Basel, Switzerland. This article is an open access article distributed under the terms and conditions of the Creative Commons Attribution (CC BY) license (http:/ / creativecommons.org/licenses/by/4.0/). 